Session 3247

\title{
Integrating Design and Manufacturing Concepts to Strengthen Advanced Technological Education Programs
}

\author{
Joseph C. Chen and Jacob Chen \\ Department of Industrial Education and Technology \\ Iowa State University, Ames, IA 50011
}

\begin{abstract}
Recent changes in the global business environment dictate the need for engineering technicians to obtain new skills in design-for-manufacturability, computer-aided design, teamwork, and communication. In addition, there is a significant workforce shortage of engineering technicians across the U.S., and particularly in the Midwest.

As part of a three-year Advanced Technical Education (ATE) project granted by the National Science Foundation (NSF), this project focuses on improving the way that the aforementioned topics are taught in community college manufacturing education programs. It also focuses on increasing the pool of qualified applicants to these programs. Four flexible course modules and instructor-training materials were developed for integration into a wide range of existing curricula. These modules integrate design for manufacturability (DFM), teamwork skills (including communication skills) and parametric solid modeling (PSM) content to improve the efficiency and effectiveness of instruction in these areas.
\end{abstract}

The modules were formed through the following three-year procedure: conceptualization, creation, pilot-testing, modification, field-testing, and evaluation. Different evaluation tools were created during the procedure, including instructor lesson surveys, student lesson surveys, student satisfaction surveys, knowledge tests in each subject area, teamwork skill evaluations, PSM skill evaluations, DFM skill evaluations, mental rotation tests (to test students' spatial visualization skills), and an overall satisfaction survey. By and large, the evaluation results proved the effectiveness and usefulness of the curriculum. This project will produce larger numbers of better-prepared workers who will contribute to a more competitive U.S. manufacturing industry. The eventual impact on students is a heightened awareness of the interaction between design and manufacturing and of the skills needed to effectively operate in a team environment.

\section{Introduction}

In many community college manufacturing programs, the introductory manufacturing design course is one of the most important courses. It is required for all students majoring in manufacturing in the community college, and it is usually among the first technical classes students ever take in their college study. It is the foundation for many other design and manufacturing classes. As such, the students' experience in the introductory manufacturing design course impacts their academic performance throughout their degree

Proceedings of the 2004 American Society for Engiheering Education Annual Conference \& Exposition Copyright@ 2004, American Society for Engineering Education 
program, and even their future career (Newcomer, et al., 1999). Therefore, it is imperative for manufacturing educators to plan the content of this course to ensure the best possible foundation for students seeking to enter manufacturing disciplines.

Introductory manufacturing design courses used to be drafting-centered. Students in the past learned hand-sketching skills and used drafting boards. A considerable amount of class time was devoted to drafting and descriptive geometry for the purpose of easy communication between the design and manufacturing departments (Howell, 1995).

This class transformed from traditional drafting and descriptive geometry to computer aided design (CAD) systems (Howell, 1995; Ault, 1999) as the rapid development of easy-to-use computers and CAD software made hand tools obsolete. Now, with the current parametric solid modeling (PSM) technology, students can spend even less time learning software packages and still be more productive in designing. It is also suggested that parametric solid modeling can enhance students' 3-D visualization skills (Devon, et al., 1994; Howell, 1995; Mohler, 1997; Newcomer, et al, 1999; Wiebe, 1992), the lack of which has been identified as one of the most important reasons why students have difficulties in this class (Sorby, et al, 1999; Strong \& Smith, 2002). The advancement of using PSM allows the traditional introductory CAD class to be reconstructed into a more effective introductory manufacturing design class that incorporates other important technical elements.

Besides CAD skills, other important technical elements that are related to the manufacturing design field were suggested in a 1995 survey exploring how to improve manufacturing and design capabilities. In this survey, 66 senior managers from 33 manufacturing companies were asked to rank a list of 56 different "best practices" in order of their importance in the manufacturing workforce. CAD skills ranked fourth on the list (see Table 1). Teamwork, communication skills, and design for manufacturability (DFM) knowledge and skills were ranked as the top three qualities that manufacturing employers look for and that entry-level employees lack (Przirembel, 1995).

Based on these industry needs, a curriculum was developed as part of a three-year Advanced Technical Education (ATE) project granted by the National Science Foundation (NSF). This curriculum combined DFM, CAD, and teamwork (including communication skills) into one integrated introductory manufacturing design class. As a result of this combination, students were able to learn CAD knowledge and skills in the context of DFM and teamwork. 
Table 1. Top five knowledge and skills manufacturing employers look for (Przirembel, 1995)

\begin{tabular}{|c|c|c|}
\hline Rank & Knowledge and Skill & $\%$ \\
\hline 1 & Teams/Teamwork & $94 \%$ \\
\hline 2 & Communication & $89 \%$ \\
\hline 3 & Design for Manufacture & $88 \%$ \\
\hline 4 & CAD Systems & $86 \%$ \\
\hline 5 & Professional Ethics & $85 \%$ \\
\hline
\end{tabular}

\section{Development of the Curriculum}

This project considered the industry's demands and the effects of those demands on future employees in order to improve teaching methods and curricula in community college manufacturing education programs. A goal-driven strategy was used throughout the development of the curriculum to effectively build the necessary components that would hold all the important design concepts and parametric solid modeling (PSM) tools together with a logical sequence to allow students to learn while reaching the final goal.

The capstone that pulls all the materials in the curriculum together is a DFM (design for manufacturability) final team project. In this final project, students are asked to analyze a product of their choice from four prepared products (or a product that they find on their own). The students work as a team to redesign the product, using the concepts of DFM that they learned to improve the product's efficiency and quality. To finish the final project, the students must present both the old design and new design to the class. Students will use the Inventor (the PSM software package) tool to analyze, redesign the products, and present the overall product redesign process. In order to successfully complete the final project, students have to learn the fundamental skills of the PSM software very well, in addition to DFM skills and teamwork skills included in the curriculum. Each of the four modules of the curriculum contains lessons in each of these three crucial subject areas: PSM, DFM, and teamwork. The proportion of each subject area in each module is roughly shown in Figure 1. 


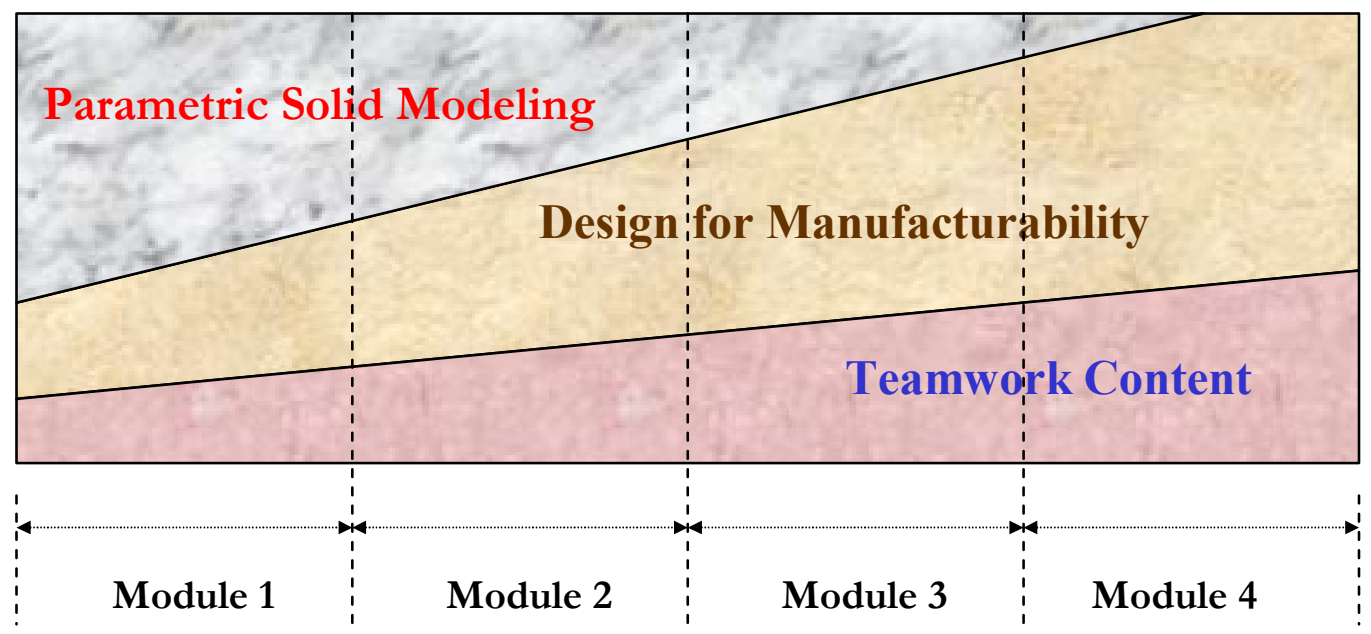

Figure 1. Proposed model for introductory manufacturing design course content

Teamwork and DFM lessons were delivered through PowerPoint presentations and class discussions. Software demonstrations were extensively used while delivering PSM lessons on the top of PowerPoint presentation and class discussion. Each lesson came with either in-class individual activities (sometimes, team activities) or take-home assignments that provide the students with hands-on experience. An instructor guide, including preview sheets, PowerPoint slides, PowerPoint presentation scripts, information sheets, demonstration sheets, and assignment sheets (in-class team activities), was developed to aid the educators in presenting and teaching the teamwork curriculum.

\section{Pilot Testing the Curriculum}

The instruction curriculum was determined and developed through the cooperative efforts of three institutions: the two community colleges in Iowa and South Dakota and Iowa State University. The resulting curriculum was further pilot tested at the two community colleges.

The curriculum developers had several questions in mind from the pilot test, including the following:

- Is the teaching sequence logical to both the students and the instructors?

- Is the time allotment appropriate?

- Are the contents interesting to students?

- Do the PowerPoint slides and PowerPoint presentation scripts make sense?

- Are the assignments reasonable?

To answer these questions, the developers designed two surveys, one for the instructors and one for the students, to be completed following the lessons. At the end of each module, the surveys were returned to the project staff at ISU. These surveys were summarized, and meetings were then held with the instructors to make the appropriate modifications. An example of an instructor survey and an example of a student survey are 
shown in Tables 2 and 3. In each of the instructors' lesson surveys, the instructors were asked to rate each lesson objective and comment on whether or not that lesson objective could be accomplished through the curriculum materials. In the students' lesson survey, they were asked to rate each lesson objective and comment on whether or not that lesson objective could be accomplished through the curriculum materials, the instructor's instruction, and other classroom activities.

Table 2. An example of an instructor lesson survey

\begin{tabular}{|l|c|c|}
\hline \multicolumn{1}{|c|}{ Lesson Objective } & $\begin{array}{c}\text { Rating } \\
\text { (1-5) }\end{array}$ & Comments \\
\hline 1. $\begin{array}{l}\text { Explain why teamwork skills are } \\
\text { essential to manufacturing organizations. }\end{array}$ & 5 & Very clear. \\
\hline \begin{tabular}{l} 
2. $\begin{array}{l}\text { Define a team charter and know what } \\
\text { should be included in a team charter. }\end{array}$ \\
\hline 3. $\begin{array}{l}\text { Explain what the facilitator of a team } \\
\text { should do. }\end{array}$
\end{tabular} & 4 & Could be more specific. \\
\hline 4. $\begin{array}{l}\text { Explain what the recorder of a team } \\
\text { should do. }\end{array}$ & 5 & Some examples? \\
\hline \begin{tabular}{l} 
5. $\begin{array}{l}\text { Write the meeting agenda for a simple } \\
\text { task. }\end{array}$ \\
\hline 6. $\begin{array}{l}\text { Identify the action items as the most } \\
\text { important part in meeting minutes. }\end{array}$
\end{tabular} & 5 & A little challenging for students. \\
\hline
\end{tabular}


Table 3. An example of a student survey

\begin{tabular}{|c|c|c|c|c|c|c|}
\hline Lesson Objective & $\begin{array}{c}\text { Rating } \\
(1-5)\end{array}$ & Stu\#1 & Stu\#2 & Stu\#3 & Stu\#4 & Stu\#5 \\
\hline $\begin{array}{l}\text { 1. Explain why teamwork } \\
\text { skills are essential to } \\
\text { manufacturing } \\
\text { organizations. }\end{array}$ & 5 & 4 & 4 & 4 & 4 & 4 \\
\hline $\begin{array}{l}\text { 2. Define a team charter and } \\
\text { know what should be } \\
\text { included in a team charter. }\end{array}$ & 5 & 3 & 4 & 4 & 5 & 3 \\
\hline $\begin{array}{l}\text { 3. Explain what the } \\
\text { facilitator of a team should } \\
\text { do. }\end{array}$ & 5 & 4 & 3 & 5 & 5 & 3 \\
\hline $\begin{array}{l}\text { 4. Explain what the recorder } \\
\text { of a team should do. }\end{array}$ & 5 & 5 & 4 & 5 & 4 & 3 \\
\hline $\begin{array}{l}\text { 5. Write the meeting agenda } \\
\text { for a simple task. }\end{array}$ & 5 & 5 & 4 & 5 & 4 & 4 \\
\hline $\begin{array}{l}\text { 6. Identify the action items } \\
\text { as the most important part } \\
\text { in meeting minutes. }\end{array}$ & 5 & 4 & 4 & 5 & 5 & 3 \\
\hline
\end{tabular}

Comments:

1. It really explained the importance of teamwork. Told how different type of people that work in manufacturing can work together.

2. Learning good teamwork skills.

3. Teamwork is very important to all designers. It helps production assembly faster.

4. It outlined what teamwork is and didn't give too much useless information.

The instructor was also asked to videotape each class to monitor progress. The resulting tape, which was viewed by the project staff, was used to observe the interaction between the students and the instructor, to learn if the content of each lesson was smoothly designed and easy to teach, and to solve problems and make improvements for each lesson. The tapes were transcribed and analyzed at Iowa State University. The tapes provided important information about the time allotted for each lesson and module. They were used to ensure that instructors were given plenty of time to teach the lessons, that the information presented in the lessons was appropriately arranged, and that the entire curriculum could be taught within one semester.

These collected surveys and transcribed tapes were used to modify the curriculum accordingly. In the meantime, researchers were also interested in knowing if the curriculum was successful in terms of student satisfaction. Consequently, a student satisfaction survey was designed and administered at the end of the instruction. 
The survey was composed of 19 survey questions (see Table 5). Results indicated that the teamwork lessons topped the student satisfaction list, which indicates that students found the teamwork lessons both satisfactory and enjoyable (Chen, 2002). Results also indicated that the materials were quite promising for full implementation into a community college curriculum. After the appropriate modifications from the pilot test were in place, researchers moved forward to field-test the curriculum.

Table 5. The results of the student satisfaction survey

(Rating Scale: 5 is excellent, 1 is poor)

\begin{tabular}{|c|c|c|c|}
\hline Rank & Item & Description & Rating \\
\hline 1.5 & 17. & $\begin{array}{l}\text { The T lessons were helpful to enhance my knowledge for } \\
\text { my career. }\end{array}$ & 4.43 \\
\hline 1.5 & 5. & The quantity of material covered was appropriate. & 4.43 \\
\hline 3 & 8. & $\begin{array}{l}\text { The final project is relevantly designed to apply the whole } \\
\text { knowledge of this course. }\end{array}$ & 4.33 \\
\hline 5 & 6. & The homework assignments were relevant. & 4.29 \\
\hline 5 & 16. & $\begin{array}{l}\text { The } T \text { lessons were easy to understand and apply in the } \\
\text { final report. }\end{array}$ & 4.29 \\
\hline 5 & 9. & $\begin{array}{l}\text { The load of teamwork assignments for each team member } \\
\text { was relevantly assigned. }\end{array}$ & 4.29 \\
\hline 7 & 14. & $\begin{array}{l}\text { The P lessons were easy to understand and apply in the } \\
\text { final project. }\end{array}$ & 4.17 \\
\hline 10.5 & 15. & $\begin{array}{l}\text { The P lessons were helpful to enhance my knowledge for } \\
\text { my future career. }\end{array}$ & 4.14 \\
\hline 10.5 & 18. & $\begin{array}{l}\text { The } \mathrm{D} \text { lessons were easy to understand and apply in the } \\
\text { final project. }\end{array}$ & 4.14 \\
\hline 10.5 & 10. & The assignments were always finished on time. & 4.14 \\
\hline 10.5 & 19. & $\begin{array}{l}\text { The D lessons were helpful to enhance my knowledge for } \\
\text { my future career. }\end{array}$ & 4.14 \\
\hline 10.5 & 4. & $\begin{array}{l}\text { The course appeared to be well organized and presented } \\
\text { logically. }\end{array}$ & 4.14 \\
\hline 10.5 & 7. & The reading assignments were appropriate. & 4.14 \\
\hline 14 & 13. & $\begin{array}{l}\text { This course has improved my ability to interpret and } \\
\text { evaluate information. }\end{array}$ & 3.86 \\
\hline 15 & 11. & $\begin{array}{l}\text { You always got feedback on time when you submitted an } \\
\text { assignment for assessment. }\end{array}$ & 3.57 \\
\hline 16 & 12. & The grading system was clear and objective. & 3.43 \\
\hline
\end{tabular}

(Note: P stands for Parametric Solid Modeling, T stands for Teamwork, and D stands for Design for Manufacturability)

Field Testing the Curriculum and Development of Evaluation Tools

The curriculum was field tested at three community colleges in Iowa, Nebraska, and South Dakota in the spring of 2003. The field test served a two-fold purpose: to further

Proceedings of the 2004 American Society for Engineering Education Annual Conference \& Exposition Copyright@ 2004, American Society for Engineering Education 
modify and improve the curriculum and to investigate the effectiveness of the curriculum in teaching teamwork. In order to do this, six different evaluation instruments were developed. In order to evaluate the effectiveness of the instruction, a pre-test composed of all six instruments was given prior to use of the instructional modules, and a post-test was given at the end of the instructional period. These instruments are described as follows:

\section{Parametric Solid Modeling (PSM):}

1. PSM knowledge test: A test composed of 20 knowledge-based multiple-choice questions about PSM based on either general PSM knowledge or specific Inventor software commands was developed to measure students' PSM knowledge. There are 20 total possible points for this test.

2. PSM skills evaluation (formative test): To evaluate these community college students' PSM skills (especially Inventor), a PSM skill evaluation test was developed. The students were asked to finish several tasks within a given amount of time. The student-created Inventor files were graded using a grading criterion list designed to assess students' hands-on PSM skills. There are 144 total possible points for this test.

3. Mental rotation test: A mental rotation test with 20 questions was developed by the staff to estimate students' spatial visualization skills. There are 40 total possible points for this test.

\section{Teamwork:}

1. Teamwork Knowledge Test: A test composed of 22 knowledge-based, multiplechoice questions about teamwork was developed by the staff to measure students' teamwork knowledge. There are 22 total possible points for this test.

2. Teamwork Skill Assessment: A test composed of 14 survey-style questions formed by the staff was used to evaluate student progress and improvement through the teamwork curriculum. Students were asked to respond to these five-point scale questions, which offered five options for each of the 14 questions. The teamwork evaluation was composed of three sections: basic teamwork knowledge (three questions), common teamwork skills (five questions), and team decision-making techniques (six questions).

\section{Design For Manufacturability (DFM):}

1. DFM knowledge test: A test composed of 18 knowledge-based questions representing DFM was developed by the staff to measure students' DFM knowledge. There are 18 total possible points for this test.

\section{Field Test Results}

\section{Parametric Solid Modeling (PSM):}

Twenty-one students finished both the pre-test and the post-test for all three instruments on PSM. The results are shown in Figure 2. 
(a)

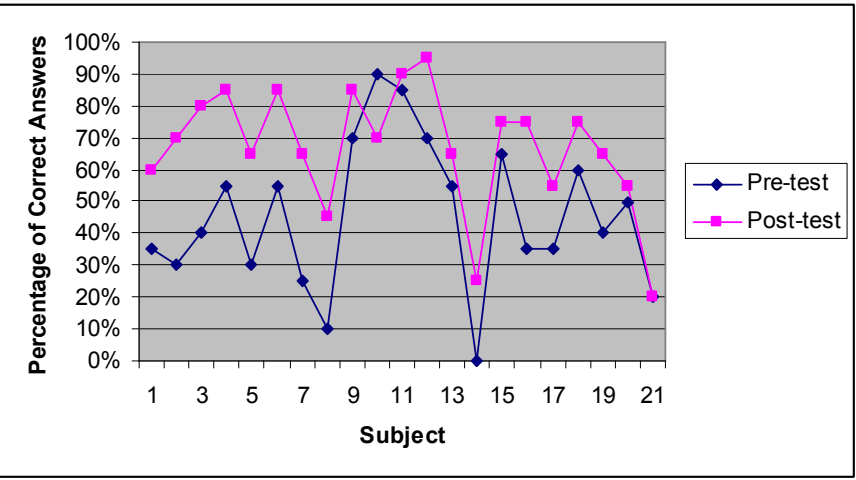

(b)

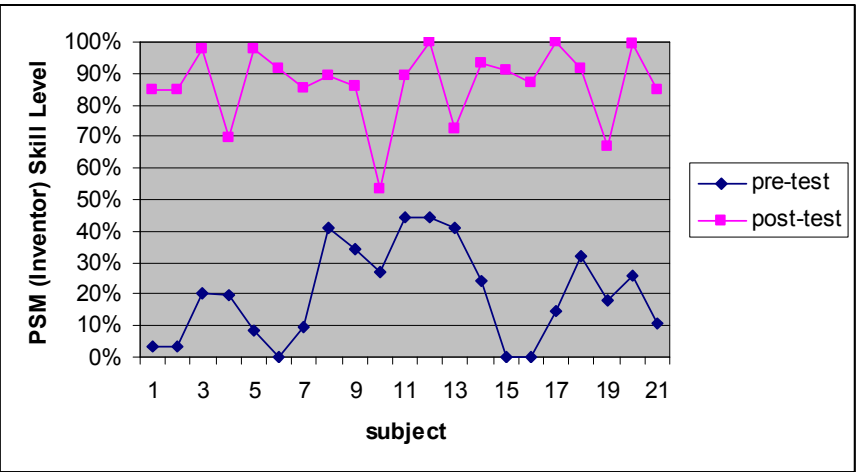

(c)

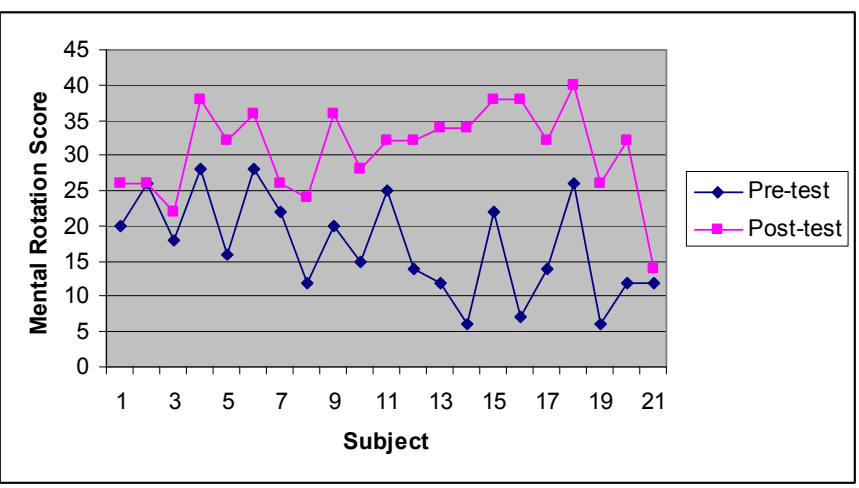

Figure 2. Results of three PSM tests: (a) the PSM knowledge test, (b) the PSM skill levels evaluation, and (c) the Mental Rotation test

1. For the knowledge test, the pre-test scores averaged 9.1 (45.5\% of 20 points) and the post-test scores averaged 13.4 (66.9\% of 20 points). A paired-samples t-test showed that participant performance was better on the post-test than on the pretest, and the number of correct answers increased significantly from the pre-test to the post-test $(\mathrm{t}=-6.2, \mathrm{p}<.01)$.

2. For the PSM skills evaluation (formative test), the pre-test scores ranged from 0 ( $0 \%$ of 144 points) to 64 (44\% of 144 points questions) and averaged $28.9(20.0 \%$ of 144 points). The post-test scores ranged from 77 (53\% of 144 points) to 144 (100\% of 144 points) and averaged 124.5 (86.5\% of 144 points). A paired- 
samples t-test showed that participant performance was better on the post-test than on the pre-test $(\mathrm{t}=-15.3, \mathrm{p}<.01)$.

3. For the Mental Rotation Test, the pre-test scores ranged from 6 (15\% of 40 points) to 28 ( $70 \%$ of 40 points) and averaged 17.2 (43\% of 40 points). The posttest scores ranged from 14 (35\% of 40 points) to 38 (95\% of 40 points), and averaged 30.8 (77\% of 40 points). A paired-samples t-test showed that participant performance was better on the post-test than on the pre-test, and the number of correct answers increased significantly from the pre-test to the post-test $(t=-7.5$, $\mathrm{p}<.01)$.

\section{Teamwork:}

1. Teamwork knowledge test: Eighteen students finished both the pre- and post-tests on teamwork knowledge. The results are shown in Figure 3.

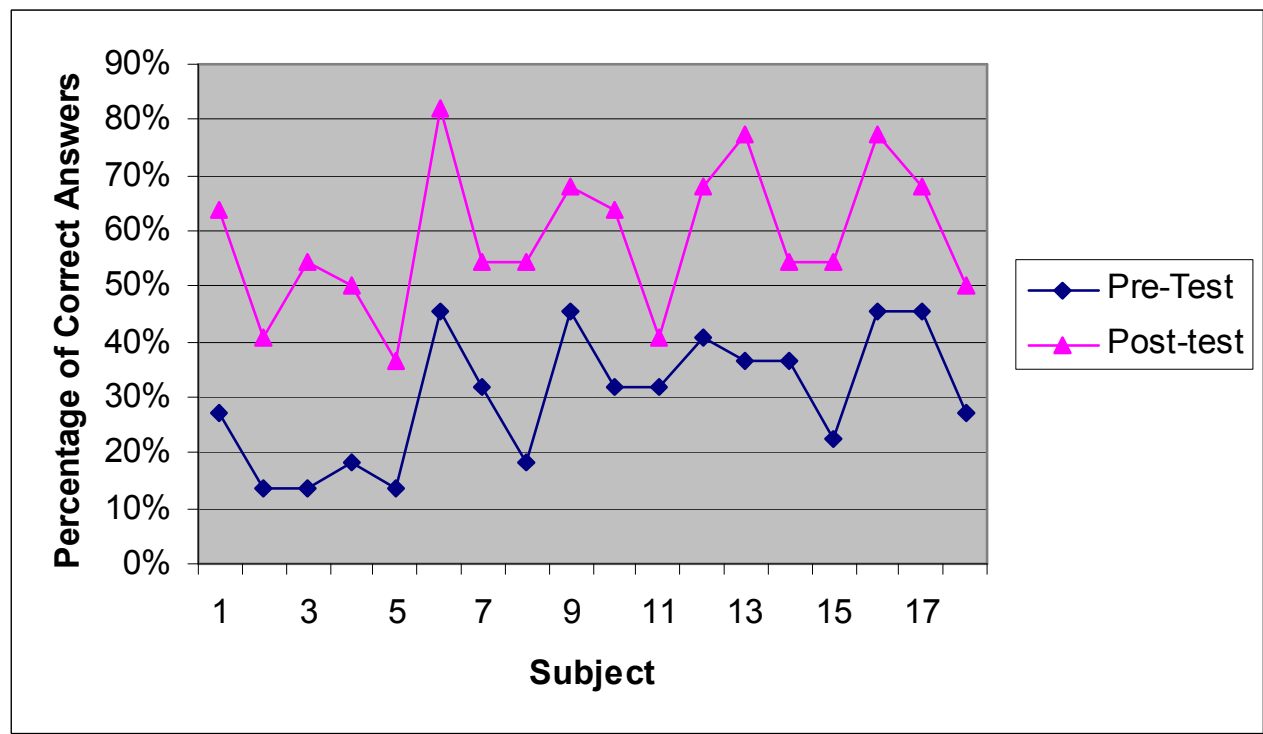

Figure 3. Percentage of correct answers on the teamwork knowledge test for both the pre-test and the post-test

The pre-test scores ranged from 3 (14\% of 22 points) to 10 (45\% of 22 points), and averaged 6.7 (34.9\% of 22 points). The post-test scores ranged from $8(36 \%$ of 22 questions) to 18 (82\% of 22 questions), and averaged $13.0(54.6 \%$ of 22 questions). A paired-samples t-test showed that participant performance was better on the post-test than on the pre-test, and the number of correct answers increased significantly from the pre-test to the post-test $(\mathrm{t}=-8.7, \mathrm{p}<.01)$.

2. Teamwork skill assessment: Comparisons between pre- and post- administration of the teamwork skill assessment are shown in Table 6. The three parts of the evaluation are shown separately in the table. The analysis was conducted for the eighteen students who were from these community colleges and finished both the pre-test and the post-test. A paired-samples t-test was used for all fifteen 
questions. It showed that the students improved more on the team-decision skills than any other skills.

Table 6. Comparisons between pre-and post administration of the Teamwork Skill Assessment

\begin{tabular}{|c|c|c|c|c|c|c|}
\hline \multirow[t]{2}{*}{ I. Basic Knowledge } & \multicolumn{2}{|c|}{ Pre-assessment } & \multicolumn{2}{|c|}{ Post-assessment } & \multirow[b]{2}{*}{$\mathrm{t}$} & \multirow[b]{2}{*}{$\mathrm{p}$} \\
\hline & Mean & $\begin{array}{c}\text { Std } \\
\text { Dev }\end{array}$ & Mean & $\begin{array}{c}\text { Std } \\
\text { Dev }\end{array}$ & & \\
\hline $\begin{array}{l}\text { A. Modern manufacturing organizations weigh } \\
\text { teamwork }\end{array}$ & 2.88 & 1.4 & 3.94 & 0.9 & 3.78 & .01 \\
\hline $\begin{array}{l}\text { B. Teamwork skills are ranked the most important } \\
\text { qualification for technicians }\end{array}$ & 3.06 & 1.4 & 3.44 & 1.0 & 0.97 & .35 \\
\hline $\begin{array}{l}\text { C. There are many types of teams in the } \\
\text { manufacturing world }\end{array}$ & 2.81 & 1.5 & 3.63 & 1.2 & 1.89 & .08 \\
\hline
\end{tabular}

\section{Common Teamwork Skills}

\begin{tabular}{|l|cc|ccc|c|}
\cline { 2 - 7 } \multicolumn{1}{l|}{} & Mean & $\begin{array}{c}\text { Std } \\
\text { Dev }\end{array}$ & Mean & $\begin{array}{c}\text { Std } \\
\text { Dev }\end{array}$ & $\mathrm{t}$ & $\mathrm{p}$ \\
\hline A. Construct a meeting agenda & 2.81 & 1.1 & 3.69 & 1.0 & 2.33 & .03 \\
\hline B. Record meeting minutes & 2.81 & 1.1 & 3.50 & 1.0 & 1.90 & .08 \\
\hline C. Become an effective and contributing member & 4.06 & 0.8 & 4.38 & 1.0 & 1.23 & .24 \\
\hline D. Solve team conflicts or team problems & 3.94 & 0.8 & 4.06 & 0.8 & 0.49 & .63 \\
\hline E. Properly communicate with others & 4.38 & 0.6 & 4.19 & 0.9 & -0.82 & .42 \\
\hline
\end{tabular}

\section{Team Decision-Making Techniques}

\begin{tabular}{|l|cc|ccc|c|}
\cline { 2 - 6 } \multicolumn{1}{l|}{} & Mean & $\begin{array}{c}\text { Std } \\
\text { Dev }\end{array}$ & Mean & $\begin{array}{c}\text { Std } \\
\text { Dev }\end{array}$ & $\mathrm{t}$ & $\mathrm{p}$ \\
\hline A. Brainstorming Technique & 4.13 & 1.2 & 4.31 & 0.8 & .59 & .57 \\
\hline B. Nominal Group Technique & 2.63 & 1.4 & 3.63 & 0.8 & 2.83 & .01 \\
\hline C. Delphi Technique & 1.81 & 1.1 & 3.31 & 1.1 & 4.11 & .00 \\
\hline D. Paired-Choice Matrix Technique & 2.06 & 1.4 & 3.56 & 1.2 & 3.67 & .00 \\
\hline E. Consensus Card Technique & 2.19 & 1.6 & 3.56 & 1.4 & 3.22 & .01 \\
\hline F. Criteria Rating Technique & 2.56 & 1.5 & 3.25 & 1.3 & 1.79 & .09 \\
\hline
\end{tabular}

\section{Design for Manufacturability (DFM):}

1. DFM knowledge test: Eighteen students finished both the pre- and the post-DFM knowledge test. The results are shown in Figure 4. 


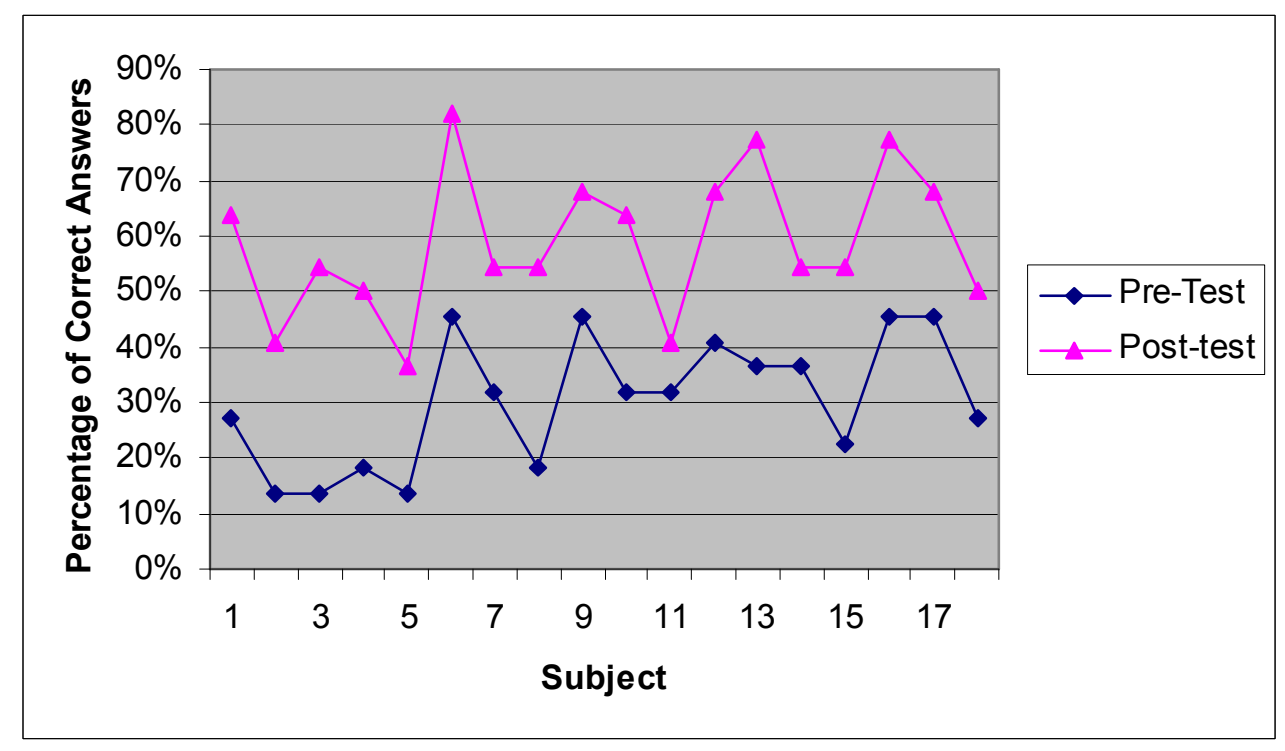

Figure 4. Percentage of correct answers on the DFM knowledge pre- and post-tests

The pre-test scores ranged from 3 (17\% of 18 points) to 10 (56\% of 18 points), and averaged 6.7 (37.0\% of 18 questions). The post-test scores ranged from 8 (44\% of 18 questions) to 18 (100\% of 18 questions), and averaged 12.4 (68.8\% of 18 questions). A paired-samples t-test showed that participant performance was better on the post-test than on the pre-test, and the number of correct answers increased significantly from the pretest to the post-test $(\mathrm{t}=-9.0, \mathrm{p}<.01)$.

\section{Conclusions}

This study investigated new ways to incorporate teamwork with DFM and PSM knowledge and skills into an introductory manufacturing design course with both the pilot and field tests, and also examined the outcome of the field test with six assessment instruments. Results comparing the knowledge and skills of the three different subject areas before and after exposure to the curriculum indicated that students gained comprehensive skills and knowledge in all three subject areas. These findings suggest that incorporating PSM, teamwork, and DFM skills and knowledge into one introductory manufacturing design class via lesson and module content and practical, realistic assignments may be beneficial to students seeking the competitive edge in the manufacturing industry.

These findings suggest that it is helpful for community college students to learn both PSM and DFM knowledge and skills by incorporating real product design into the curriculum. They also suggest that 3-D parametric solid modeling can be taught at the community college level in a relatively short period of time with satisfactory results if user-friendly software for the classroom is carefully selected. 
However, these results also indicate that instructors play a crucial role in student teamwork training success. Instructors may need more professional training on the subject before they can positively affect students. Therefore, this research suggests that an extended study on teamwork in the following areas will be necessary: instructor training on teamwork and its impacts on students' teamwork learning; appropriate length of exposure, retention of knowledge, and use of the teamwork skills by students in other manufacturing courses. 


\section{Acknowledgments}

Funding for this project by the National Science Foundation's Advanced Technological

Education program (DUE \# 0053249) is gratefully acknowledged.

\section{References}

Ault, H. K. (1999). 3-D geometric modeling for the $21^{\text {st }}$ century. The Engineering Design Graphics Journal, 63 (2), 33-42.

Chen, J. C. (2002). Annual progress report (June 2001 - May 2002) for the NSF ATE program (Award \#0053249). Ames, IA: Iowa State University, Department of Industrial Education and Technology.

Devon, R., Engel, R. S., Foster, R. J., Sathianathan, D., \& Turner, G. F. W. (1994). The effect of solid modeling software on 3-D visualization skills. The Engineering Design Graphics Journal, 58 (2), 4-11.

Howell, S. K. (1995). The use of a parametric feature based CAD system to teach introductory engineering graphics. The Engineering Design Graphics Journal, 60 (1), 27-35.

Mohler, J. L. (1997). An instructional method for the AutoCAD modeling environment. The Engineering Design Graphics Journal, 61 (1), 5-13.

Newcomer, J. L., Raudebaugh, R. A., McKell, E. K., \& Kelley, D. S. (1999). Proceedings of $29^{\text {th }}$ ASEE/IEEE Frontiers in Education Conference, San Juan, Puerto Rico, November 10-13, 1999.

Przirembel, C. (1995). Integrating the Product Realization Process (PRP) into the Undergraduate Curriculum, ASME International, New York.

Sorby, S. A. (1999). Developing 3-D spatial visualization skills. The Engineering Design Graphics Journal, 55 (1), 21-32.

Wiebe, E. N., Branoff, T. J., \& Hartman, N. W. (2003). Teaching geometry through dynamic modeling in introductory engineering graphics. The Engineering Design Graphics Journal, 67 (2), 12-20. 
JOSEPH C. CHEN is a Professor in the Department of Industrial Education and Technology at Iowa State University. He received both his M.S. and Ph.D. degrees in Industrial Engineering at Auburn University in 1990 and 1994, respectively. He assumes the roles of project director and PI of a National Science Foundation project entitled "Competitive Manufacturing by Design." His research interests include: manufacturing system control, manufacturing system design, design for manufacturing education, smart CNC machining, simulation as a design tool, simulation techniques, and cellular manufacturing system design.

JACOB CHEN is a Post-Doc Associate in the Department of Industrial Education and Technology at Iowa State University. He received his Ph.D. degree in Industrial Technology at Iowa State University in 2003. He assumes the role of manager of the project. His research interests include: QFD applications, spatial visualization, automatic machining, and CAD teaching improvement. 